\title{
GERMINAÇÃO E MORFOLOGIA DE SEMENTES E PLÂNTULAS DE Albizia edwallii (Hoehne) Barneby \& J. W. Grimes ${ }^{1}$
}

\author{
MANOELA MENDES DUARTE ${ }^{2 *}$, JAÇANAN ELOÍSA DE FREITAS MILANI ${ }^{2}$, CHRISTOPHER THOMAS BLUM², \\ ANTONIO CARLOS NOGUEIRA ${ }^{2}$
}

\begin{abstract}
RESUMO - O presente trabalho teve como objetivo caracterizar a morfologia de sementes e plântulas e avaliar a germinação de sementes de Albizia edwallii submetidas a diferentes substratos e temperaturas. Na caracterização física foram avaliados o peso de mil sementes, número de sementes por quilo e grau de umidade. Para a determinação das características morfológicas foi avaliada a biometria de 50 sementes, bem como as suas características internas e externas. A germinação foi conduzida sob três temperaturas $\left(20^{\circ} \mathrm{C}, 25^{\circ} \mathrm{C}\right.$ e $\left.30{ }^{\circ} \mathrm{C}\right)$ e três substratos (areia, vermiculita e papel mata-borrão), com cinco repetições de 40 sementes por tratamento, em esquema fatorial 3 × 3 e delineamento inteiramente casualizado. As variáveis avaliadas foram porcentagem de germinação, índice de velocidade de germinação, tempo médio de germinação e índice de sincronização. $O$ peso de mil sementes foi de 47,7 g, enquanto que o número de sementes por quilo foi de 20.964 para o grau de umidade de $13,1 \%$. As sementes possuem forma elíptica, não apresentam endosperma e possuem funículo persistente. A germinação é epígea e a plântula é fanerocotiledonar, estando completamente formada aos 15 dias. As temperaturas de $20{ }^{\circ} \mathrm{C}$ e $25^{\circ} \mathrm{C}$ propiciaram os maiores percentuais de germinação, quais sejam, 42 e $38 \%$, respectivamente, e índice de velocidade de germinação (IVG). A utilização de areia como substrato proporcionou percentuais de germinação superiores aos demais substratos avaliados. Assim, recomenda-se a utilização de areia como substrato e as temperaturas de $20^{\circ} \mathrm{C}$ e $25^{\circ} \mathrm{C}$ para os testes de germinação de A. edwalli.
\end{abstract}

Palavras-chave: Fabaceae. Temperatura. Substrato. Biometria.

\section{GERMINATION AND MORPHOLOGICAL OF SEED AND SEEDLING OF Albizia edwallii (Hoehne) Barneby \& J. W. Grimes}

\begin{abstract}
This study aimed to characterize the morphology of seeds and seedlings and evaluate the germination of seeds of Albizia edwallii submitted to different substrates and temperatures. In physical characterization were evaluated thousand seed weight, the number of seeds per kilogram and moisture content. To determine the morphological characteristics, it was evaluated the biometry of 50 seeds, as well as its internal and external characteristics. Germination was conducted at three temperatures $\left(20^{\circ} \mathrm{C}, 25^{\circ} \mathrm{C}\right.$ and $\left.30^{\circ} \mathrm{C}\right)$ and three substrates (sand, vermiculite and blotting paper) with five replications of 40 seeds per treatment, in a factorial 3 x 3 and completely randomized design. The variables were germination percentage, germination rate index, mean germination time, and synchronization index. The thousand seed weight was $47.7 \mathrm{~g}$, while the number of seeds per kilo was 20.964 for the moisture content of $13.1 \%$. The seeds have an elliptical shape, no endosperm and have persistent funiculus. Germination is epigeal, and the seedling is phanerocotylar being fully formed at 15 days. Temperatures of $20^{\circ} \mathrm{C}$ and $25^{\circ} \mathrm{C}$ provide the highest germination rates, 42 and $38 \%$, respectively, and germination speed index (GSI). The use of sand as a substrate provided better germination percentage than the other substrates. Thus, it is recommended to use sand as a substrate and temperatures of $20^{\circ} \mathrm{C}$ and $25^{\circ} \mathrm{C}$ in A. edwalli germination tests.
\end{abstract}

Keywords: Fabaceae. Temperature. Substrate. Biometry.

\footnotetext{
*Autor para correspondência

${ }^{1}$ Recebido para publicação em 14/11/2014; Aceito em 28/04/2015.

${ }^{2}$ Departamento de Ciências Florestais, Universidade Federal do Paraná, Rua Lothário Meissner, 632, Jardim Botânico, CEP: 80210-170, Curitiba (PR), Brasil; manu-florestal@hotmail.com.
} 


\section{INTRODUÇ̃̃̃O}

Albizia edwallii (Hoehne) Barneby \& J. W. Grimes (Fabaceae) é uma espécie arbórea típica de florestas secundárias do bioma Mata Atlântica, com ampla ocorrência natural em diversas fitofisionomias. Ela caracteriza-se por possuir porte médio, com cerca de $20 \mathrm{~m}$ de altura e $60 \mathrm{~cm}$ de diâmetro, sendo amplamente recomendada para arborização urbana e plantios de recuperação de áreas degradadas (CARVALHO, 2010).

Independente de sua considerável distribuição geográfica, A. edwallii sofreu com a drástica redução da cobertura vegetal, haja vista ser raramente registrada em levantamentos fitossociológicos e, quando listada, o número de indivíduos amostrado é sempre baixo, como verificado nos estudos de Moscovich, Keller e Borhen (2005) e Loregian et al. (2012). Segundo a IUCN (2014), A. edwallii enquadra-se como espécie vulnerável à extinção, ameaçada principalmente pelo declínio e fragmentação de suas áreas de ocorrência, o que torna os estudos ecológicos e silviculturais importantes para sua conservação.

As sementes são uma importante garantia de sobrevivência das espécies vegetais. Constituídas em sua grande maioria por embrião, endosperma e tegumento, esses elementos são fortemente influenciados por diferenças ambientais ou adaptações evolutivas, podendo variar morfologicamente entre espécies ou até mesmo entre indivíduos (ABUD et al., 2010).

Os estudos morfológicos de sementes e plântulas fornecem informações sobre a biologia e os processos germinativos (OLIVEIRA, 1993). Essas pesquisas permitem inferências sobre a determinação de famílias, gêneros e espécies (OLIVEIRA, 1993), que são importantes fontes para subsidiar a escolha de espécies em programas de recuperação de áreas degradadas e conservação ecológica (DUTRA; FILHO; DINIZ, 2008).

Nesse sentido, diversos trabalhos têm sido realizados com o intuito de fornecer esse tipo de informação, como os desenvolvidos por Rego et al. (2011), com Blepharocalyx salicifolius (H.B.K.), Berg e Myrceugenia gertii Landrum, Haliski (2013), com Casearia decandra Jacq, Loureiro et al. (2013), com Amburana cearensis (Fr. All.) A.C. Smith e Pimenta, Zuffellato-Ribas e Laviola (2014), com Jatropha curcas L., além do trabalho pioneiro desenvolvido por Barroso et al. (1999). Entretanto, muito se tem ainda a ser pesquisado, principalmente para espécies raras ou ameaçadas de extinção, como é o caso de A. edwallii.

Além da caracterização morfológica cabe salientar a importância dos estudos que foquem o potencial germinativo das sementes. Características como viabilidade, dormência, condições do ambiente (água, luz, temperatura) e tipo de substrato determinam diferentes respostas para cada espécie, o que torna prioritário o conhecimento dessas condições nos estudos de sementes florestais (CARVALHO;
NAKAGAWA, 2012).

O potencial germinativo das sementes é avaliado a partir de testes de germinação, os quais são conduzidos em laboratórios, sob condições controladas. De acordo com Lorentz e Nunes (2013), a realização destes testes permite avaliar e comparar a qualidade fisiológica de diferentes lotes de sementes. As recomendações de condução dos testes de germinação estão presentes nas Regras para Análise de Sementes (BRASIL, 2009), que continuadamente vem sendo atualizadas com as informações de espécies florestais, sendo estudos desta natureza de grande valia.

Diante do exposto, objetivou-se caracterizar a morfologia de sementes e plântulas e avaliar a germinação de $A$. edwallii submetida a diferentes substratos e temperaturas.

\section{MATERIAL E MÉTODOS}

Os frutos foram coletados em cinco matrizes localizadas em remanescente de floresta Ombrófila mista no munícipio de Fernandes Pinheiro (PR) $\left(27^{\circ}\right.$ $24^{\prime} 35,87^{\prime}$ 'S; 50 $32^{\circ}$ ' 45,16' 'W e altitude de $824 \mathrm{~m}$ ). Os frutos foram coletados diretamente das árvores, e após 15 dias de secagem, em ambiente de laboratório, as sementes foram retiradas dos legumes, acondicionadas em sacos plásticos e armazenadas em refrigerador $\left(8{ }^{\circ} \mathrm{C}\right.$ e $70 \%$ UR do ambiente) por 120 dias até a realização dos experimentos.

Para a caracterização física das sementes foi determinado o peso de 1000 sementes e o número de sementes por quilo. Para isso foram utilizadas oito amostras de 100 sementes, pesadas em balança de precisão (0,001 g) (BRASIL, 2009). O grau de umidade foi obtido a partir de três amostras de 100 sementes, secas em estufa a $105 \pm 3{ }^{\circ} \mathrm{C}$ por 24 horas (BRASIL, 2009). Com base no grau de umidade e no peso de 1000 sementes foi calculado também a biomassa seca dessas sementes.

Para a caracterização biométrica foram utilizadas 50 sementes, tomadas aleatoriamente da amostra. Com auxílio de um paquímetro mensurou-se o comprimento, a largura e espessura, sendo o comprimento medido da base até o ápice e a largura e espessura medidas na linha mediana das sementes.

A morfologia foi descrita caracterizando os aspectos externos e internos da semente. Externamente foram observados a coloração, textura, consistência do tegumento, forma, bordo, posicionamento do hilo e micrópila, pleurograma e funículo. Para o estudo da morfologia interna as sementes foram hidratadas em água destilada e a partir de secções transversais e longitudinais observadas e descritas as seguintes características: presença ou não de endosperma; cotilédones; e eixo hipocótilo-radícula. Todas as observações foram realizadas com o auxílio de lupa estereoscópica de mesa. As características morfológicas das sementes foram descritas com base no 
trabalho realizado por Barroso et al. (1999).

Para a caracterização morfológica das fases de germinação e características das plântulas 50 sementes foram semeadas em caixas plástica, tipo gerbox $11 \times 11 \times 3,5 \mathrm{~cm}$ contendo como substrato uma folha de papel mata-borrão, mantidas em germinador tipo Biochemical Oxygen Demand (B.O.D.) a $25^{\circ} \mathrm{C}$, sob luz contínua. As avaliações foram realizadas diariamente após a primeira emissão de radícula, sendo consideradas plântulas quando os eofilos se encontravam totalmente formados.

Em todas as etapas de germinação até a formação da plântula foram descritos e demostrados os seguintes elementos vegetativos: tipo de germinação; radícula e raiz; colo; hipocótilo; epicótilo; cotilédones; e protofilos. As ilustrações morfológicas de semente e plântula foram feitas manualmente, a partir de material bem desenvolvido e representativo de cada fase. Os termos empregados para essas fases estão de acordo com Barroso et al. (1999).

Para avaliar o efeito da temperatura e do substrato na germinação o experimento seguiu a premissa de um delineamento inteiramente casualizado. Foi adotado o arranjo fatorial $3 \times 3$ organizado em três temperaturas $\left(20{ }^{\circ} \mathrm{C}, 25{ }^{\circ} \mathrm{C}\right.$ e $\left.30{ }^{\circ} \mathrm{C}\right)$ e sobre três substratos (areia, vermiculita e papel mata-borrão), cinco repetições de 40 sementes para cada tratamento, acondicionadas em caixas gerbox e alocadas em germinadores do tipo Mangelsdorf, sob luz constante.

A areia foi uniformizada em peneira de malha de $0,8 \mathrm{~mm}$, lavada e esterilizada em estufa a $200{ }^{\circ} \mathrm{C}$ durante duas horas, sendo utilizada para cada gerbox 100 gramas, umedecida com $35 \mathrm{~mL}$ de água destilada, representando $60 \%$ da capacidade de retenção do substrato. Para o substrato vermiculita foram utilizadas 20 gramas em cada gerbox, acrescidas de $70 \mathrm{~mL}$ de água. Para o substrato papel foi utilizada uma folha de papel mata-borrão umedecida com $7 \mathrm{~mL}$ de água destilada, sendo 2,5 vezes o peso do substrato. Foi realizada a reposição da água sempre que necessário. Antes da instalação dos testes de germinação, em adaptação ao que foi proposto por Carvalho (2009) para Albizia niopoides (Spruce ex Benth.)
Burkart, todas as sementes foram imersas em água a $80{ }^{\circ} \mathrm{C}$ por 10 minutos visando à superação da dormência.

As avaliações foram realizadas diariamente até que a germinação se estabilizasse por três dias consecutivos. Os dados obtidos foram utilizados para a determinação da porcentagem de germinação, índice de velocidade de germinação (IVG) (MAGUIRE, 1962), tempo médio de germinação e índice de sincronização (LABORIOU, 1983), sendo que o critério de germinação utilizado foi a protrusão da radícula com comprimento igual ou superior a $0,5 \mathrm{~cm}$.

Os dados foram submetidos ao teste de Bartlett para verificação da homogeneidade e posteriormente a análise de variância. Havendo diferença significativa, a comparação de médias foi realizada por intermédio do teste de Tukey, em nível de 5\% de probabilidade de erro.

\section{RESULTADOS E DISCUSSÃO}

Albizia edwallii apresentou o peso de mil sementes igual a 47,7 g e um número de sementes por quilo de 20.964. Por ocasião do armazenamento, as sementes se encontravam com $13,1 \%$ de grau de umidade, o que repercute em uma biomassa seca de mil sementes igual a 41,4 g. De acordo com Carvalho (2009), Albizia niopoides apresenta cerca de 36 mil sementes por quilo, com grau de umidade de 9,9\%. Fowler, Carpanezzi e Zuffellato-Ribas (2006) descreveram um peso de mil sementes de 27,28 g para Albizia hassleri (sinônimo de Albizia niopoides). Essa variação no peso das sementes já foi comentada por Roshetko (1997) para o gênero Albizia.

Quanto à sua morfologia e biometria, as sementes apresentaram forma elíptica, com comprimento médio de $7,78 \mathrm{~mm}$, largura média de $5,73 \mathrm{~mm}$ e espessura média de $1,38 \mathrm{~mm}$ (Tabela 1$)$. A semente de $A$. edwallii é funiculada (funículo persistente), com micrópila pequena e circular de cor marrom, localizados na região basal. A testa é lisa e dura, de cor verde-acinzentada e com presença de pleurograma aberto (Figura 1).

Tabela 1. Comprimento, largura e espessura das sementes de Albizia edwallii.

\begin{tabular}{ccccc}
\hline Dimensões (mm) & Mínimo & Média & Máximo & Coeficiente de variação (\%) \\
\hline Comprimento & 6,76 & 7,78 & 8,99 & 5,79 \\
Largura & 4,42 & 5,73 & 7,01 & 8,03 \\
Espessura & 1,07 & 1,38 & 1,63 & 8,68 \\
\hline
\end{tabular}

No que toca à morfologia interna, as sementes de $A$. edwallii não apresentam endosperma, sendo o embrião dominante e linear, de cor branca e eixo embrionário (hipocótilo-radícula) curto, reto e cônico. Os cotilédones são semicarnosos, lisos, retos, sem nervuras e de cor creme.

O pleurograma consiste em uma marca lateral na superfície de certas sementes, originada pela interrupção na paliçada da exotesta ou mesmo pela diferença nas camadas externas da testa, sendo sua fisiologia ainda desconhecida (BARROSO et al., 1999). Gunn (1984) ressalta que a presença de pleurograma se torna um caráter bastante válido para a identificação de espécies, considerando ainda que do ponto de vista da ontogenia o pleurograma pode apresentar diferenças entre gêneros, tribos e subfamílias. 
(A)

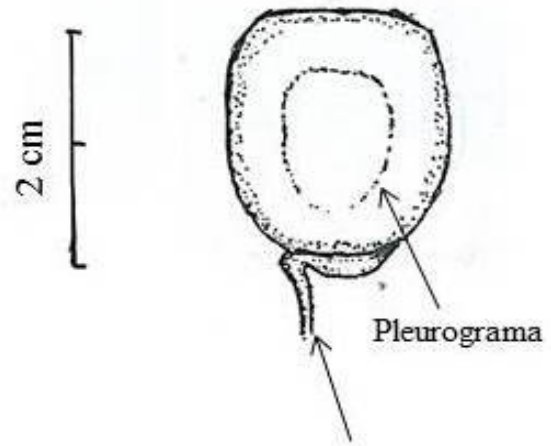

Funiculo
(B)

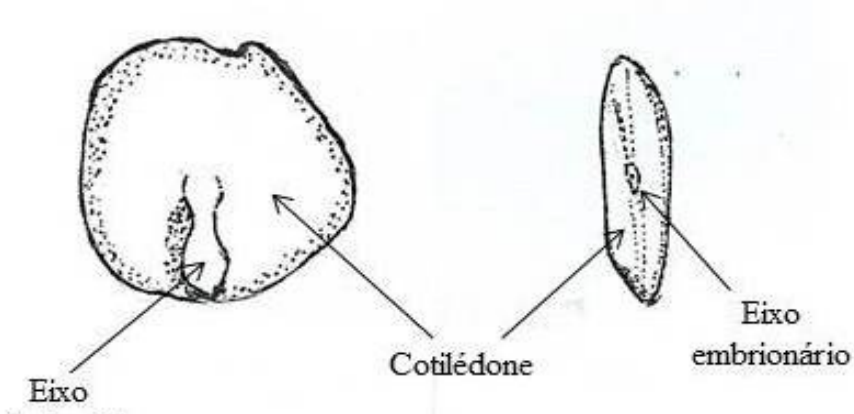

embrionário
B)

(C)

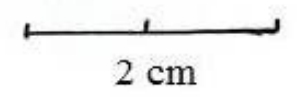

Figura 1. Morfologia externa e interna da semente de Albizia edwallii. (A) morfologia externa; (B) morfologia interna; (C) corte transversal.

A germinação de sementes de A. edwallii é do tipo epígea e a plântula é fanerocotiledonar, pois durante a germinação seus cotilédones são visíveis e elevados acima do nível do solo e expandem-se liberando o tegumento (CAVICHIOLO; BOERGER; MARQUES, 2009). Inicia-se no quarto dia e se estende até o décimo quinto dia com a protrusão e expansão da radícula e subsequente elevação do hipocótilo. Inicialmente os cotilédones permanecem envoltos pelo tegumento e aproximadamente após 12 dias a plântula libera e abre os cotilédones, iniciando -se o desenvolvimento dos eofilos (Figura 2). Albizia niopoides também apresenta germinação epígea e fanerocotiledonar, sendo que sua emergência tem início de seis a 15 dias com sementes que sofreram superação de dormência (CARVALHO, 2009).

Os cotilédones de $A$. edwallii são de cor verde, opostos, cordiformes, membranáceos, com base truncada, ápice retuso e margens inteiras. Os eofilos são compostos paripinados, peciolados, de consistência herbácea, glabros, de cor verde, com cerca de sete pares de folíolos sésseis subpostos (Figura 2). A raiz primária inicialmente é de cor branca e pilosa, sendo o hipocótilo longo, cilíndrico, verde claro e glabro.
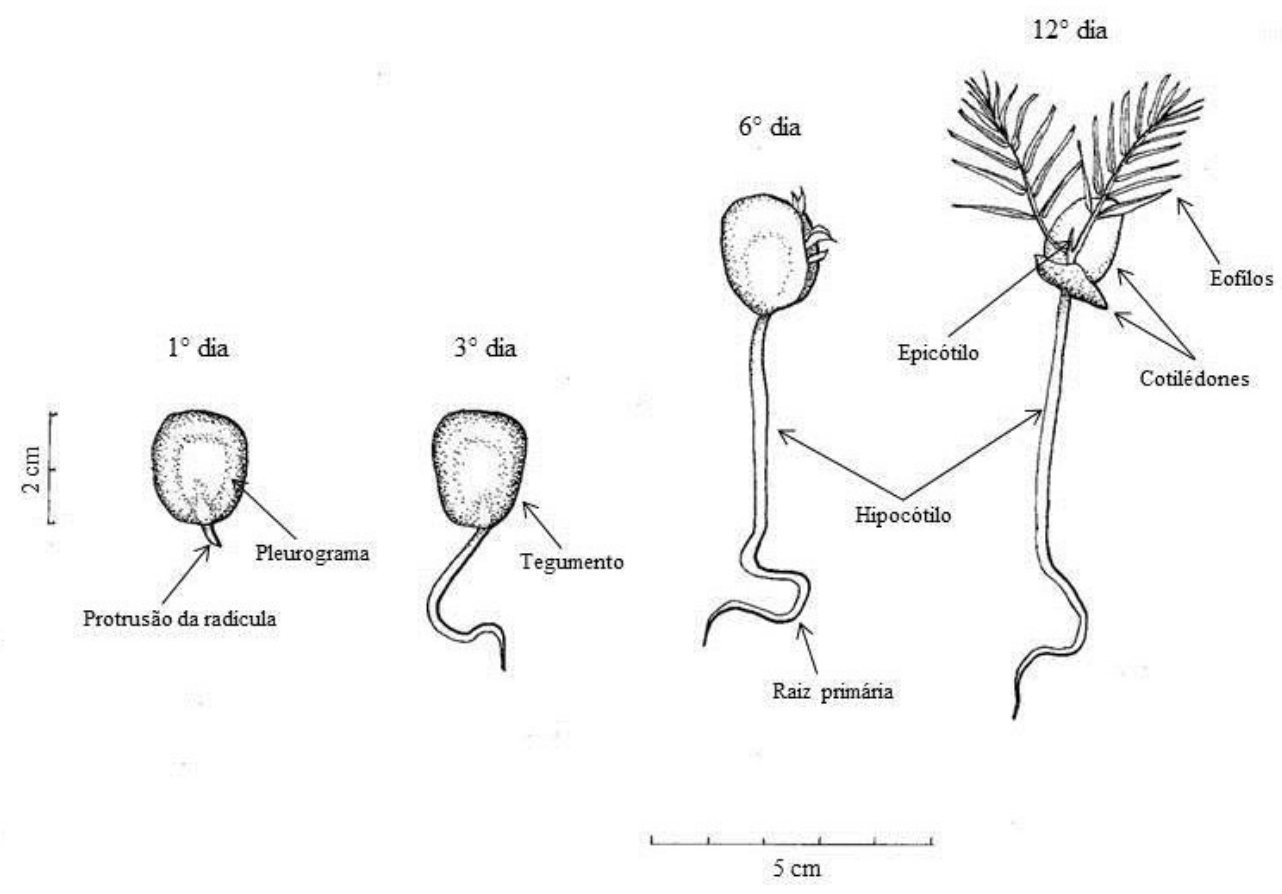

Figura 2. Morfologia de plântula e fases da germinação de Albizia edwallii. 
$\mathrm{Na}$ Tabela 2 pode-se observar a análise de variância para as variáveis temperatura e substrato sobre a germinação das sementes de Albizia edwallii. A germinação média obtida foi de $35 \%$. Gonzales, Paula e Valeri (2009) em seu estudo com uma espécie do mesmo gênero (Albizia niopoides) obtiveram germinação média de $90 \%$, sendo notável a diferença de valores encontrados para as espécies de mesmo gênero. A baixa porcentagem de germinação no presente estudo pode ser decorrente de características específicas do lote de sementes utilizado.

Tabela 2. Análise de variância para porcentagem de germinação $(\mathrm{G})$, índice de velocidade de germinação (IVG), índice de sincronização (E) e tempo médio de germinação (TMG) de sementes de Albizia edwallii.

\begin{tabular}{cccccc}
\hline \multirow{2}{*}{ FV } & GL & \multicolumn{4}{c}{ Quadrado médio } \\
\cline { 3 - 6 } & & G & IVG & E & TMG \\
\hline Temperatura & 2 & $1213,96^{*}$ & $3,72^{*}$ & $0,969^{\text {ns }}$ & $11,69 \mathrm{~ns}$ \\
Substrato & 2 & $548,36^{*}$ & $0,756^{\text {ns }}$ & $1,789^{*}$ & $65,61^{*}$ \\
Interação & 4 & $37,96^{\text {ns }}$ & $1,828^{\mathrm{ns}}$ & $1,147^{*}$ & $2,62^{*}$ \\
\hline Média & - & 34,89 & 2,06 & 2,69 & 10,26 \\
CV (\%) & - & 25,78 & 27,28 & 23,56 & 13,8 \\
\hline
\end{tabular}

" significativo ao nível de $5 \%$ de probabilidade;

${ }^{\text {ns }}$ não significativo $(\mathrm{p}>=0,05)$.

No que diz respeito à porcentagem de germinação, não houve interação entre as fontes de variação testadas, mas diferença significativa entre as temperaturas e entre os substratos. Na Figura 3-A são apresentadas as médias da porcentagem de germinação para os três substratos testados. A areia demonstrou ser o substrato mais efetivo para $A$. edwallii, diferenciando-se estatisticamente dos demais e proporcionando $42 \%$ de germinação. Os substratos vermiculita e papel mata-borrão não diferiram estatisticamente entre si, apresentando 33 e $30 \%$ de germinação, respectivamente.
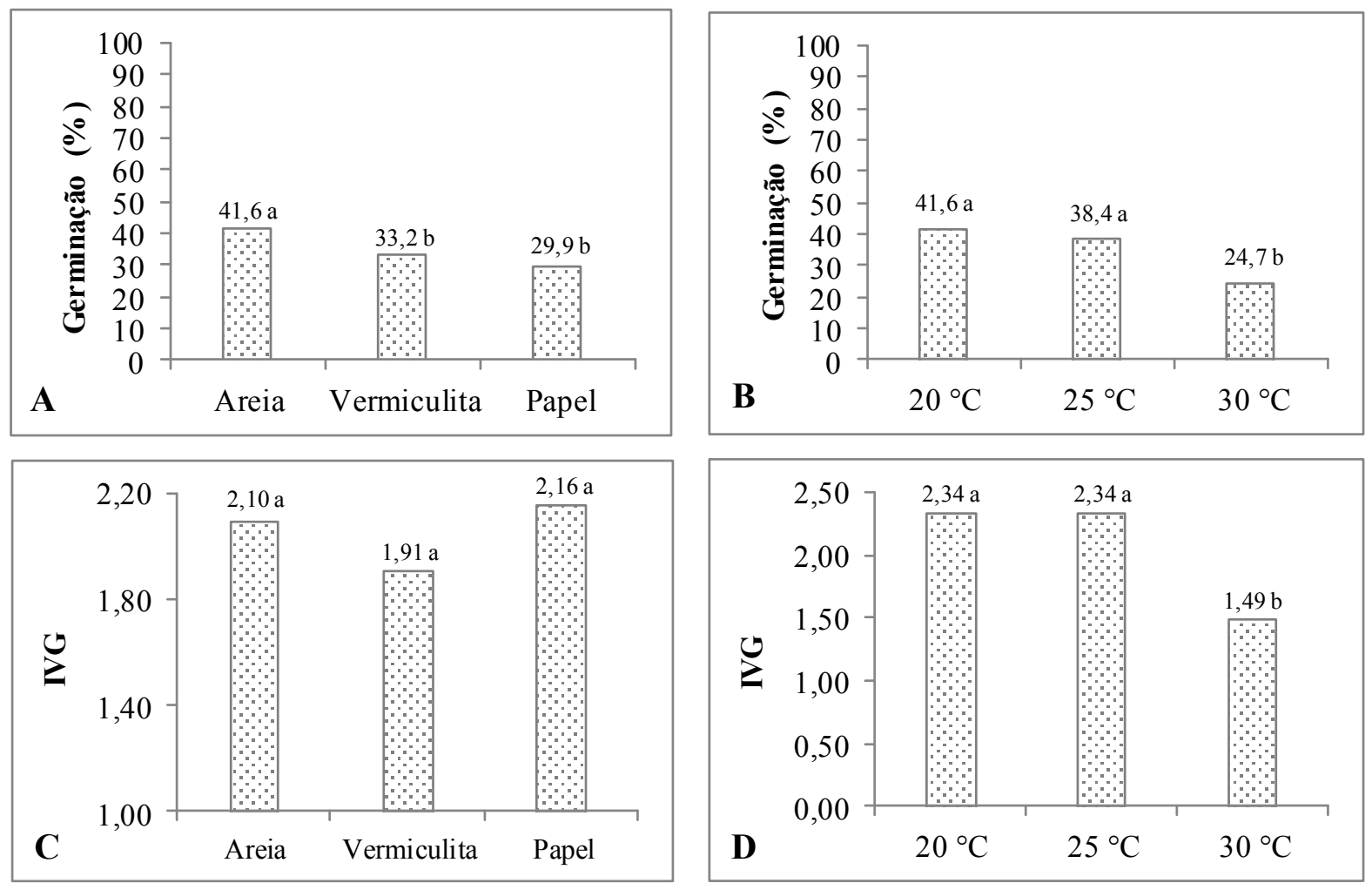

Figura 3. Germinação (A e B) e índice de velocidade de germinação (IVG) (C e D) de sementes de Albizia edwallii em diferentes temperaturas e substratos. 
Resultados contrários foram observados por Scalon, Mussury e Almeida (2003) para a germinação de Caesalpinia pelthophoroides Benth., sendo que a areia apresentou as menores porcentagens de germinação. Da mesma forma, Miranda et al. (2012) observaram menores taxas de germinação para sementes de Anadenanthera peregrina (L.) Speg. com o substrato areia, sugerindo que a capacidade de retenção de água do substrato possa ter influenciado nesse resultado.

Observações feitas por Mondo et al. (2008) apontam que a vermiculita tem sido utilizada com bons resultados para as sementes florestais devido a sua boa capacidade de absorção e retenção de água, diferente do que foi observado no presente trabalho para a porcentagem de germinação no substrato vermiculita. Nesse sentido, são observadas algumas contradições na literatura em que as sementes de espécies florestais possuem diferentes necessidades de substrato, o que evidencia a necessidade de testes para o conhecimento dos melhores substratos a serem utilizados para as diferentes espécies (BOCCHESE et al., 2008).

Com relação às temperaturas (Figura 3-B), resultados superiores foram encontrados quando as sementes foram submetidas a $20{ }^{\circ} \mathrm{C}$ e $25^{\circ} \mathrm{C}$, apresentando 42 e $38 \%$ de germinação, respectivamente, porém não diferiram estatisticamente. A temperatura de $30{ }^{\circ} \mathrm{C}$ se mostrou a menos adequada para a germinação de sementes de $A$. edwallii, diferindo estatisticamente das demais e apresentando o menor valor de germinação $(25 \%)$.

Os resultados divergem do que foi encontrado por Gonzales, Paula e Valeri (2009), os quais verificaram a existência de diferença no comportamento germinativo entre as temperaturas para Albizia niopoides, tendo maior desempenho de germinação submetido a $30{ }^{\circ} \mathrm{C}$. Brancalion et al. (2010), ao compilarem diversos estudos sobre temperaturas e germina- ções de espécies nativas brasileiras, verificaram que a grande maioria das espécies de Mata Atlântica requerem temperatura ótima de germinação de $25{ }^{\circ} \mathrm{C}$, como verificado para $A$. edwallii.

Para o índice de velocidade de germinação verificou-se que não ocorreu interação entre as fontes de variação substrato e temperatura. Com relação aos substratos testados não houve diferença significativa, sendo que o papel mata-borrão demonstrou valor ligeiramente superior aos demais (Figura 3-C). As sementes de $A$. edwallii iniciaram a emissão da radícula no quarto dia após serem semeadas nos substratos, demonstrando, de forma geral, elevada velocidade de germinação para a espécie.

Ao estudarem a germinação de Anadenanthera peregrina em diferentes substratos, Miranda et al. (2012) observaram que a germinação ocorreu de forma mais lenta quando as sementes foram colocadas em areia. Os autores ainda salientaram que entre a vermiculita e o papel filtro não houve diferença significativa, sendo que esses substratos apresentaram maior IVG.

Dos tratamentos testados, apenas a temperatura de $30{ }^{\circ} \mathrm{C}$ apresentou diferença estatística em relação às demais, com valor de IVG $=1,49$, sendo este inferior aos encontrados para as demais temperaturas (Figura 3-D). Com relação ao IVG médio, o valor encontrado no presente trabalho foi de 2,1 , sendo este inferior ao encontrado por Gonzales, Paula e Valeri (2009) para Albizia niopoides (IVG $=5,06$ ). Como salientado por Nascimento (2000), temperaturas muito baixas ou muito altas poderão alterar tanto a velocidade quanto a porcentagem final de germinação. Em geral, temperaturas baixas reduzem, enquanto que temperaturas altas aumentam a velocidade de germinação.

A Tabela 3 apresenta as médias para as variáveis índice de sincronização (E) e tempo médio de germinação (TMG).

Tabela 3. Índice de sincronização (E) e tempo médio de germinação (TMG) de sementes de Albizia edwallii em diferentes temperaturas e substratos.

\begin{tabular}{cccc}
\hline \multirow{2}{*}{ Temperatura $\left({ }^{\circ} \mathrm{C}\right)$} & \multicolumn{3}{c}{$\mathrm{E}$} \\
\cline { 2 - 4 } & Areia & Vermiculita & Papel \\
\hline 20 & $2,61 \mathrm{aA}$ & $2,56 \mathrm{aA}$ & $2,85 \mathrm{aA}$ \\
25 & $3,27 \mathrm{aA}$ & $3,01 \mathrm{aA}$ & $2,59 \mathrm{aA}$ \\
30 & $3,22 \mathrm{aA}$ & $2,55 \mathrm{aAB}$ & $1,59 \mathrm{bB}$ \\
\hline \multirow{2}{*}{ Temperatura $\left({ }^{\circ} \mathrm{C}\right)$} & & TMG & Papel \\
\hline 20 & Areia & Vermiculita & $8,51 \mathrm{aC}$ \\
25 & $13,91 \mathrm{aA}$ & $11,28 \mathrm{aB}$ & $8,31 \mathrm{abC}$ \\
30 & $11,77 \mathrm{abA}$ & $10,08 \mathrm{abB}$ & $8,17 \mathrm{bC}$ \\
\hline
\end{tabular}

Média seguida por letras iguais minúsculas na mesma coluna e maiúscula na mesma linha não diferem entre si, ao nível de $5 \%$ pelo teste de Tukey. 
No que se refere ao índice de sincronização das sementes é possível observar que houve interação entre as fontes de variação (Tabela 3). Para a interpretação das médias do índice de sincronização é importante destacar que quanto menor o valor mais sincronizada é a germinação em relação ao tempo. Diante disso, o substrato papel aliado à temperatura de $30{ }^{\circ} \mathrm{C}$ proporcionaram a combinação mais eficiente para a sincronização da germinação das sementes de $A$. edwallii, apresentando valor de $\mathrm{E}=1,59$. Ainda nesta temperatura foi possível observar o bom desempenho do índice de sincronização com a vermiculita de $\mathrm{E}=2,55$.

$\mathrm{O}$ índice de sincronização não se relaciona com a porcentagem de germinação, mas com a forma como esta foi distribuída no tempo. As sementes submetidas à temperatura de $30{ }^{\circ} \mathrm{C}$ e ao substrato papel apresentaram as menores taxas de germinação, entretanto obtiveram um melhor índice de sincronização. Isto pode ser explicado pelo fato da germinação de todas as sementes ter ocorrido em um curto período de tempo, portanto mais sincronizada. Diferente do que ocorreu para os outros substratos e temperaturas, que tiveram menores índices de sincronização, decorrentes da germinação mais espaçada no tempo.

Da mesma forma que o índice de sincronização, o melhor tempo médio de germinação está associado aos menores valores observados. Na Tabela 3 verificou-se a interação entre as fontes de variação, na qual a combinação menos eficiente foi areia e 20 ${ }^{\circ} \mathrm{C}$, ocasionando o tempo médio de germinação de 13,91 dias.

A combinação de $30{ }^{\circ} \mathrm{C}$ com substrato papel apresentou desempenho superior, sendo esse o período de 8,17 dias. Entretanto, essa temperatura proporcionou resultados inferiores para a variável porcentagem de germinação e IVG (Tabela 3). De acordo com Santana e Ranal (2000), quanto menor for o tempo médio maior será a velocidade de germinação das sementes, haja vista que o tempo médio e a velocidade média são duas grandezas inversamente proporcionais.

Trabalhando com sementes de Hyptis pectinata L. os autores Santos Neto et al. (2008) verificaram que sementes expostas à temperatura de $20{ }^{\circ} \mathrm{C}$ tiveram aumento do TMG quando comparadas àquelas submetidas a $35{ }^{\circ} \mathrm{C}$, ou seja, temperaturas mais baixas proporcionam maior período de tempo para que ocorra a germinação.

\section{CONCLUSÕES}

As sementes de Albizia edwallii possuem forma elíptica e não apresentam endosperma, sendo o embrião dominante e linear. $\mathrm{O}$ eixo embrionário é curto, reto e cônico. Apresentam funículo persistente, com micrópila pequena e circular. $\mathrm{E}$ a germinação é epígea e a plântula é fanerocotiledonar.
As temperaturas de 20 ou $25^{\circ} \mathrm{C}$ e o substrato areia foram as mais indicadas para condução do teste de germinação.

\section{AGRADECIMENTOS}

Os autores agradecem ao professor Dr. Carlos Vellozo Roderjan pela ilustração da morfologia da plântula de Albizia edwallii.

Agradecemos a Sociedade Chauá pelo apoio e por disponibilizar as sementes utilizadas para execução deste trabalho.

\section{REFERÊNCIAS}

ABUD, H. F. et al. Morfologia de sementes e plântulas de cártamos. Revista Ciência Agronômica, Fortaleza, v. 41, n. 2, p. 259-265, 2010.

BARROSO, G. M. et al. Frutos e sementes: morfologia aplicada à sistemática de dicotiledôneas. Viçosa, MG: UFV, 1999. 443 p.

BOCCHESE, R. A. et al. Efeito de diferentes tipos de solos na germinação de sementes de Tabebuia heptaphylla, em casa telada. Cerne, Lavras, v. 14, n. 1, p. 62-67, 2008.

BRANCALION, P. H. S.; NOVEMBRE, A. D. L. C.; RODRIGUES, R. R. Temperatura ótima de germinação de sementes de espécies arbóreas brasileiras. Revista Brasileira de Sementes, Londrina, v. 32 , n. 4, p. 15-21, 2010

BRASIL. Ministério da Agricultura, Pecuária e Abastecimento. Secretaria de Defesa Agropecuária. Regras para análise de sementes. Brasília: MAPA/ ACS, 2009. 399 p.

CARVAlHO, N. M.; NAKAGAWA, J. Sementes: ciência tecnologia e produção. 4.ed. Jaboticabal: Funep, 2012. 590 p.

CARVALHO, P. E. R. Espécies arbóreas brasileiras. Brasília, DF: Embrapa Informação Tecnológica; Colombo, PR: Embrapa Florestas, 2010. 644 p. (Coleção Espécies Arbóreas Brasileiras, v. 4).

CARVALHO, P. E. R. Farinha-seca: Albizia niopoides. Colombo: Embrapa Florestas, 2009. p. 8 (Comunicado Técnico, 226).

CAVICHIOLO, L. E; BOEGER, M. R. T; MARQUES. M. C. M. Estrutura dos eófilos e cotilédones de quatro tipos de plântulas da Floresta de Restinga, Paraná. IHERINGIA, Série. Botânica, Porto Alegre, v. 64, n. 2, p. 5-14, 2009. 
DUTRA, A. S.; FILHO, S. M.; DINIZ, F. O. Germinação de sementes de albízia (Albizia lebbeck (L.) Benth.) em função da luz e do regime de temperatura. Revista Caatinga, Mossoró, v. 21, n. 1, p. 75-81, 2008.

FOWLER, J. A. P.; CARPANEZZI, A. A.; ZUFFELLATO-RIBAS, K. C. Tecnologia para o Manejo Adequado de Sementes de Farinha-seca. Boletim de Pesquisa Florestal, Colombo, n. 53, p. 195-208, 2006.

GONZALES, J. L. S.; PAULA, R. C.; VALERI, S. $\mathrm{V}$. Teste de condutividade elétrica em sementes de Albizia hassleri (Chodat) burkart. FabaceaeMimosoideae. Revista Árvore, Viçosa, v. 33, n. 4, p. 625-634, 2009.

GUNN, C. R. Fruits and seeds of genera in the subfamily Mimosoideae (Fabaceae). Washington: United States Department of Agriculture, 1984. 193 p. (Technical Bulletin 1681).

HALISKI, S. et al. Caracterização morfológica de frutos, sementes, plântulas e germinação de sementes de Casearia decandra. Pesquisa Florestal Brasileira, Colombo, v. 33, n. 75, p. 253-259, 2013.

IUCN - International Union for Conservation of Nature. The IUCN Red List of Threatened Species. Disponível em: <www.iucnredlist.org $>$. Acesso em 05 nov. 2014

LABORIAU, L. G. A germinação das sementes. Washington: Organização dos Estados Americanos, 1983. $174 \mathrm{p}$.

LOREGIAN, A. C. et al. Padrões espaciais e ecológicos de espécies arbóreas refletem a estrutura em mosaicos de uma floresta subtropical. Acta Botanica Brasilica, Feira de Santana, v. 26, n. 3, p. 593606, 2012.

LORENTZ, L. H.; NUNES, U. R. Relações entre medidas de qualidade de lotes de sementes de arroz. Revista Ciência Agronômica, Fortaleza, v. 44, n. 4, p. 798-804, 2013.

LOUREIRO, M. B. et al. Aspectos morfoanatômicos e fisiológicos de sementes e plântulas de Amburana cearensis (Fr. All.) A.C. Smith (Leguminosae - Papilionoideae). Revista Árvore, Viçosa, v. 37, n. 4, p. 679-689, 2013.

MAGUIRE, J. D. Speed of germination-aid in selection and evaluation for seedlig emergence and vigor. Crop Science, Madison, v. 2, n. 1, p. 176-177, 1962.

MIRANDA C. C et al. Germinação de sementes de Anadenanthera peregrina (L.) Speg. com diferentes substratos em condições laboratoriais. Floresta e Ambiente, Seropédica, v. 19, n.1, p. 26-31, 2012.

MONDO, V. H. V. et al. Teste de germinação de sementes de Parapiptadenia rigida (Benth.) Brenan (Fabaceae). Revista Brasileira de Sementes, Londrina, v. 30, n. 2, p. 177-183, 2008.

MOSCOVICH, F.; KELLER, H.; BORHEN, A. Indicadores de impacto ambiental de plantaciones forestales - componente vegetal. Ciência Florestal, Santa Maria, v. 15, n. 1, p. 21-32, 2005.

NASCIMENTO, W. M. Temperatura x germinação. Seed News, Pelotas, v. 4, n. 4, p. 44-45, 2000

OLIVEIRA, E. C. Morfologia de plântulas. In: AGUIAR, I. B.; PIÑA-RODRIGUES, F.C.M.; FIGLIOLIA, M.B (Ed). Sementes florestais tropicais. Brasília: ABRATES, 1993. p. 175-213.

PIMENTA, A. C.; ZUFFELLATO-RIBAS, K. C.; LAVIOLA, B. G. Morfologia de frutos, sementes e plântulas de Jatropha curcas. Revista Floresta, Curitiba, v. 44, n. 1, p. 73-80, 2014

REGO, S. S. et al. Caracterização morfológica e germinação de sementes de Curitiba prismatica (D. Legrand) Salywon \& Landrum. Revista Brasileira de Sementes, Londrina, v. 33, n. 4, p. 616-625, 2011 .

ROSHETKO, J. M. Seed treatments for Albizia species. In: NEPTALE ZABALA (Ed). International Workshop on Albizia and paraserianthes species, , Bislig, Surigao del Sur. 1997. p. 37-43.

SANTANA, D. G.; RANAL, M. A. Análise estatística na germinação. Revista Brasileira de Fisiologia Vegetal, Campinas, v. 12 (Edição Especial), p. 205 237,2000

SANTOS NETO, A. L. S. et al. Influência da luz e da temperatura na germinação de sementes de sambacaitá (Hyptis pectinata (L.) Poit). Revista Brasileira de Agrociência, Pelotas, v. 14, n. 4, p. 19-26, 2008 .

SCALON, S. P. Q.; MUSSURY, R. M.; ALMEIDA, K. A. Efeito do álcool e substrato na germinação de sementes de sibipiruna (Caesalpinia pelthophoroides Benth.) colhidas no chão e retiradas da vagem. Ciência e Agrotecnologia, Lavras, v. 27, n. 2 , p. 389-392, 2003. 